\title{
Tertiary Amine Methacrylate based Polymers as Corrosion Inhibitors in Double Distilled Water. Part I
}

\author{
A. Büyüksağiş ${ }^{a, *}$, H. Y. Çiçek ${ }^{b}$, and V. Bütün ${ }^{c}$ \\ a Afyon Kocatepe University, Chemistry Department, Afyonkarahisar, Turkey \\ ${ }^{b}$ Mining Etude Search, Cukurambar, Ankara, Turkey \\ ${ }^{c}$ Eskisehir Osmangazi University, Chemistry Department, Eskisehir, Turkey \\ *e-mail:absagis@aku.edu.tr \\ Received September 19, 2018; revised March 27, 2019; accepted April 15, 2019
}

\begin{abstract}
In the current study, the inhibitive performances of tertiary amine methacrlate based water soluble diblock copolymers on the corrosion behaviour of AISI 304 stainless steel were investigated in double distilled water ( $\mathrm{DDW}$, at $\mathrm{pH}=7.6$ ) using potentiodynamic polarisation, electrochemical impedance spectroscopy (EIS), scanning electron microscopy (SEM), energy dispersive X-ray analysis (EDX), atomic force microscopy (AFM) and inductively coupled plasma optical emmision spectrometry (ICP OES) methods. Related diblock copolymers were poly[2-(dimethylamino)ethylmethacrylate] (PDMA), poly[2-(diethylamino)ethylmethacrylate] (PDEA), poly[2-(diisopropylamino)ethylmethacrylate] (PDPA) homopolymers and poly[2-(dimethylamino)ethylmethacrylate]-b-poly[methylmethacrylate] (PDMA- $b$-PMMA), poly[2-(diethylamino)ethylmethacrylate]-bpoly[methylmethacrylate] (PDEA- $b$-PDMA) and poly[2-(diisopropylamino)ethylmethacrylate]-b-poly[2-(dimethylamino)ethylmethacrylate] (PDPA- $b$-PDMA). Diblock copolymers having different molecular weight and different comonomer ratios. Polarisation curves indicated that all the studied polymers were acting as a mixed type inhibitors. All electrochemical measurements showed that inhibition efficiencies increased with an increase in the inhibitor concentration. It was determined that the increase of inhibitor efficiency by concentration resulted from the adsorption of polymers to metal surface, and the adsorption fitted to Langmuir adsorption equation. Adsorption equilibrium constant $\left(K_{\text {ads }}\right)$ and free energy of adsorption $\left(\Delta G_{\text {ads }}\right)$, which were thermodynamic parameters of adsorption were calculated by benefiting from the drawn adsorption isotherms. The variation in inhibitive efficiency mainly depended on the type and the nature of the substituents present in the inhibitor molecule and also depended on the molecular weight of the inhibitors. The best inhibition in DDW showed VB207 diblock copolymer. Surface images obtained with SEM, EDX and AFM methods, determined by verifying these results that inhibitors decreased the dissolution of metal, and prevented the corrosion.
\end{abstract}

Keywords: corrosion, polymer, AISI 304 stainless steel, adsorption, inhibitor

DOI: $10.1134 / \mathrm{S} 2070205119050058$

\section{INTRODUCTION}

Cross-linked polymer membranes made from tertiary amines methacrylates such as ethyl diethyl and dimethyl amino ethyl methacrylate, polyethylene glycol derivatives and other methacrylates have been used in $\mathrm{pH}$-sensitive medicine release devices [1]. Over the last decade, they have received considerable interest due to their potential applications of double hydrophilic diblock copolymers with $\mathrm{pH}$, salt and temperature sensitive characteristics. These applications are, up to now, emulsions in water of medicine delivery systems and gene therapy, interchangeable amphiphiles, mineralization templates, crystal growth modifiers, induced nanoreactors for metal colloid systems, desalting membranes and two incompatible polymers. Such diblock copolymers are completely soluble in water as unimers under certain conditions.
PDMA- $b$-PDEA copolymers have increased the interest for many applications such as biosensor, membrane, medicine delivery systems, substrate for cell culture, isolation of biomolecules, and control of enzyme activity. It exhibits specific solution properties such as freshening, temperature, and $\mathrm{pH}$ susceptibility [2-5].

In the current study, the inhibitive performances of tertiary amine methacrylate based water soluble poly[2-(dimethylamino)ethylmethacrylate]- $b$-poly[methylmethacrylate] (PDMA-b-PMMA), poly[2(diethylamino)ethylmethacrylate]- $b$-poly[methylmethacrylate] (PDEA-b-PDMA) and poly[2-(diisopropylamino)ethylmethacrylate]- $b$-poly[2-(dimethylamino)ethylmethacrylate] (PDPA- $b$-PDMA) diblock copolymers different molecular weights and comonomer compositions were investigated on the corrosion behaviour of AISI 304 stainless steel using their con- 1 
Table 1. The chemical composition ( wt \%) of the AISI 304 stainles steel

\begin{tabular}{c|c|c|c|c|c|c|c|c|c|c}
\hline $\mathrm{Fe}$ & $\mathrm{Cr}$ & $\mathrm{C}$ & $\mathrm{Si}$ & $\mathrm{P}$ & $\mathrm{S}$ & $\mathrm{Mn}$ & $\mathrm{Mo}$ & $\mathrm{Cu}$ & $\mathrm{Ni}$ & $\mathrm{N}$ \\
\hline 70.55 & 18.45 & 0.03 & 0.48 & 0.02 & 0.29 & 1.50 & 0.48 & 0.48 & 8.56 & 0.48 \\
\hline
\end{tabular}

taining various concentrations $\left(1 \times 10^{-2} \mathrm{M}, 1 \times 10^{-3} \mathrm{M}\right.$, $\left.1 \times 10^{-4} \mathrm{M}, 1 \times 10^{-5} \mathrm{M}\right)$ in double distilled water at $\mathrm{pH}$ $=7.6$. Potentiodynamic polarisation, electrochemical impedance spectroscopy (EIS), scanning electron microscopy(SEM), energy dispersive X-ray analysis (EDX), atomic force microscopy (AFM) and inductively coupled plasma optical emmision spectrometry (ICP-OES) methods were used to determine the inhibitive performances of related polymers.

\section{MATERIALS AND METHODS}

Gamry Referance 600 Potentiostat/Galvanostat ZRA and Echem Analyst Soft Program were used in electrochemical experimental studies. The $\mathrm{pH}$ measurements were performed with a Hanna model $\mathrm{pH}$ meter. Bandelin ultrasonic water bath was used for preparation of solutions and cleaning of electrodes. A heated magnetic stirrer (Velp) was used when regular mixing process was required. All weighing operations were performed on an AS220/C/2 model (RADWAG) analytical balance. In electrochemical studies, pure water used for stock and buffer solutions preparation was obtained from TKA Smart 2 Pure brand (Made in Germany) ultrapure water device. Then bidistilled water was got from pure water through double distilled water system designed from glass materials.

In this study, the AISI 304 steel was used as the working electrode, saturated calomel electrode (DKE) as the reference electrode, and platinum wire as the counter electrode. All the current-potential curves obtained in the experiments were measured against DKE, and the results were given relative to this electrode [2, 3]. The composition of the AISI 304 steel used as the working electrode is given in Table 1.

A cylindrical steel electrode with a surface area of $0.19625 \mathrm{~cm}^{2}$ was placed in a teflon so that only one of the surface area was exposed to medium. To avoid the potential drop between the saturated calomel electrode and the working electrode, the DKE was brought close to the working electrode with the help of a Lugin capillary. Before the electrochemical tests, electrodes were polished with 1200 grids of abrasive paper and then for surface cleaning of electrodes, they were respectively rinsed with technical acetone, technical alcohol and double distilled water at $30^{\circ} \mathrm{C}$ and 15 minutes ultrasonic bath. The surface of the cleaned electrode was immersed in the test solution. The solution was purged with nitrogen gas for 30 minutes and the experiment was started.
The potential curves of the steel in aqueous media were obtained using the potentiodynamic method. Current-potential curves were obtained at a scanning speed of $1 \mathrm{mVs}^{-1}$ by a potenodynamic method. EIS measurements were performed at a measured open circuit potential using a $10 \mathrm{mV}$ amplitude between $1 \times$ $10^{4}$ and $1 \times 10^{-1} \mathrm{~Hz}$.

The surface cleaned electrodes were placed in $100 \mathrm{~mL}$ brown glass bottles and added to $20 \mathrm{~mL}$ of DDW $+10^{-2} \mathrm{M}$ polymer solutions for surface analyses. The mouths of the bottles were closed and waited for a week in a water bath at $22^{\circ} \mathrm{C}$. After a week the electrodes were removed from the polymer solution and their surface analyses were made. SEM images were taken from a LEO 1430 VP brand SEM microscope. EDX analysis studies (Röntec EDX instrument based on SEM microscope and Quantax soft program) were also carried out on these samples. AFM analysis made by Parksistem brand AFM was displayed at a resolution of $0.02 \mathrm{~nm}$ at a scanning speed of $50 \mu \mathrm{m} \times 50 \mu \mathrm{m} X Y$. Elements analysis ( $\mathrm{Cr}, \mathrm{Cu}, \mathrm{Mn}, \mathrm{Fe}, \mathrm{Ni})$ in $\mathrm{DDW}+$ $10^{-2}$ copolymer concentration was carried out by Spectro Genesis Fee model inductively coupled plasma optical emmision spectrometry (ICP-OES).

\section{RESULTS AND DISCUSSIONS}

Polymers are known to be better adsorbent than their monomers. Thus, polymers are expected to be better corrosion inhibitors than that of monomers. Their performance has improved due to the fact that their have multiple adsorption sites to associate with the metal surface of oligos or polymeric materials. Polymer offers two advantages:

(1) a single polymer chain can be displaced by many water molecules on the metal surface, making the process entropy positive, and

(2) the presence of multiple binding sites further slows the desorption process of the polymers.

Amines and their derivatives are well known corrosion inhibitors which improve the adsorption and protection effect of displacement of multiple bonds. The aryl groups exhibit better inhibitory properties than the alkyl groups due to their aromatic-bull-containing occurrences. The incorporation of more than one functional group within a molecule is believed to help lock the inhibitor on a strong metal surface. Cationic polyelectrolytes find extensive industrial and commercial applications [6]. The molecule structure of some tertiary amine methacrylate monomer used in this research is given in Fig. 1.

The diblock copolymers namely PDPA- $b$-PDMA, PDMA- $b$-PMEMA and PDMA- $b$-PDEA synthesized by the group transfer polymerization (GTP). All of them are soluble molecularly in acidic solutions due to protonation of tertiary amine nitrogen atoms. However, PDEA and PDPA blocks (of diblock copolymers PDMA- $b$-PDEA and PDMA- $b$-PDPA) could be 
adjusted hydrophobically by increasing the solution $\mathrm{pH}$. If the $\mathrm{pH}$ value exceeds 6.4 for PDPA block and 7.3 for PDEA block for their block copolymers with PDMA, both blocks will collapse due to dehydration and their hydrophobicities. Because the average degree of protonation falls below the critical value and the chains become hydrophobic. Thus, they form well-defined core shell miscellaneous (PDEA-core, PDPA-core miscelles) in the absence of any organic decomposer in basic conditions [7,8].

The PMMA block in PDMA- $b$-PMMA diblock copolymer is a hydrophobic block and this polymer can form PMMA-core micelles at all $\mathrm{pH}$ values. This block copolymer can be converted into a water-insoluble form by precipitation via increasing either ionic strength in the medium or the solution temperature.

The composition, number average molecular weight $\left(M_{\mathrm{n}}\right)$, molecular weight distribution $\left(M_{\mathrm{w}} / M_{\mathrm{n}}\right)$ of the polymers used in this study are given in Table 2.

\subsection{Electrochemical Results and Discussions}

The activities of the inhibitors dependent on the nature of the metallic surfaces, condition, and chemical composition of the metal. Also, stability of the inhibitor film formation adsorbed on the metal surface to protect the metal from corrosion depends on some physicochemical properties of the molecule, the interest of the functional groups, the aromaticity, the possible steric hindrance, the electron density of the donors, the type of corrosive environment, and the nature of the interaction between the inhibitor and the metal surface. This interaction is usually explained by the formation of physical or chemical adsorptive film on the metal surface. The adsorption of the inhibitors is cathodic, anodic or capable of blocking both reactions. Electrostatic interaction between charged inhibitor molecules and charged active sites on the metal surface causes physical adsorption [9-11].

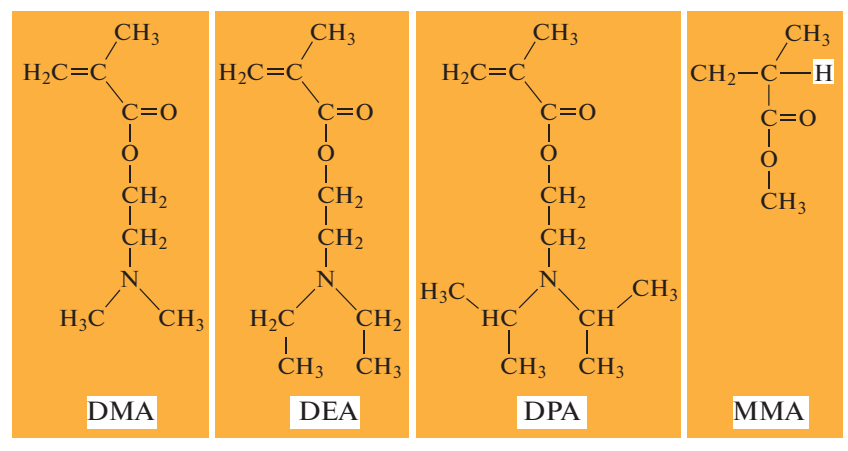

DMA: 2-(dimethylamino)ethyl metacrylate DPA: 2-(diizoprohylamino)ethyl metacrylate DEA: 2-(dimethylamino)ethyl metacrylate MMA: 2-Methyl metacrylate

Fig. 1. The molecular structure of the monomers used in the synthesis of (co)polymers some tertiary amine methacrylate monomer.

The current-potential curves were obtained using the potentiodynamic method in inhibitor and inhibitor-free solutions. The corrosion characteristics determined in this study were corrosion rate $\left(i_{\text {cor }}\right)$, corrosion potential $\left(E_{\text {corr }}\right)$, anodic and cathodic Tafel slopes ( $\beta$ a and $\beta c$ ), surface coating fraction $(\theta)$ and inhibition $\%$ values. The percentage inhibition value was the degree of corrosion prevention of the inhibitor added to the solution. In other words, the inhibitor was to prevent corrosion by covering the surface. Corrosion rates were obtained by corrosion potential extrapolation from the anodic and cathodic Tafel regions, percentage of inhibition was found using the following equation;

$$
\text { inhibition\% }=\left[1-\frac{i_{\text {corr }}(\text { with inhibitor })}{i_{\text {corr }}(\text { without inhibitor })}\right] \times 100 \text {. }
$$

Experimental studies were performed in the double distilled water $+x \mathrm{M}$ diblock copolymers solutions see

Table 2. The number average molecular weight $\left(M_{\mathrm{n}}\right)$, molecular weight distribution $\left(M_{\mathrm{w}} / M_{\mathrm{n}}\right)$ and comonomer ratio (mole $\left.\%\right)$ values of the used diblock copolymers

\begin{tabular}{c|l|c|c|c|c}
\hline $\begin{array}{c}\text { Polymer } \\
\text { code }\end{array}$ & \multicolumn{1}{|c|}{ Polymer } & $\begin{array}{c}\text { Theoric }{ }^{\mathrm{b}} \text { (copolymer } \\
\text { composition } \\
\text { mole \%) }\end{array}$ & $\begin{array}{c}\text { Experimental }^{\mathrm{b}} \\
\text { (copolymer composition } \\
\text { mole \%) }\end{array}$ & $\begin{array}{c}M_{\mathrm{n}}^{\mathrm{a}}(\mathrm{GPC}) \\
\mathrm{g} / \mathrm{mol}\end{array}$ & $M_{\mathrm{w}} / M_{\mathrm{n}}{ }^{\mathrm{a}}(\mathrm{GPC})$ \\
\hline VB201 & PDMA-b-PMMA & $80 / 20$ & $78 / 22$ & 15300 & 1.07 \\
VB206 & BDMA-b-PMMA & $80 / 20$ & $78 / 22$ & 23990 & 1.07 \\
VB207 & BzDMA-b-PMMA & $80 / 20$ & $78 / 22$ & 24300 & 1.07 \\
VB258 & PDMA-co-PMMA & $80 / 20$ & $77 / 23$ & 13900 & 1.07 \\
VB406 & PDEA-b-PDMA & $20 / 80$ & $20 / 80$ & 34125 & 1.05 \\
VB501 & PDPA-b-PDMA & $30 / 70$ & $21 / 79$ & 12500 & 1.11 \\
VB510 & PDPA-b-PDMA & $20 / 80$ & $22 / 78$ & 19300 & 1.15 \\
VB511 & PDPA-b-PDMA & $20 / 80$ & $20 / 80$ & 1.12 \\
\hline
\end{tabular}

a: determined by GPC, b: determined by ${ }^{1} \mathrm{H}$ NMR spectroscopy 


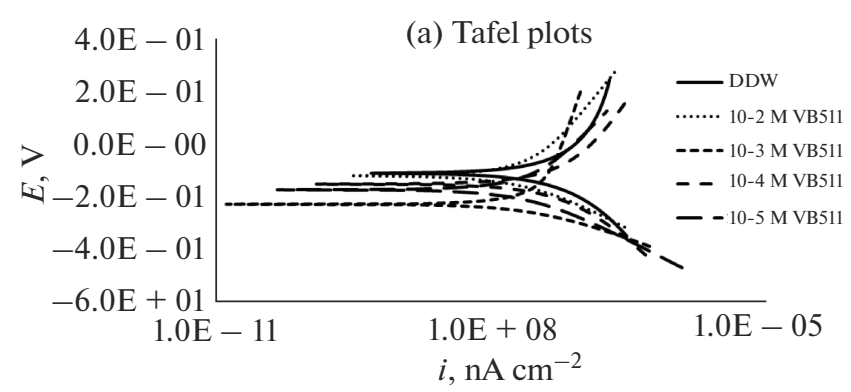

(b) Nyquist plots

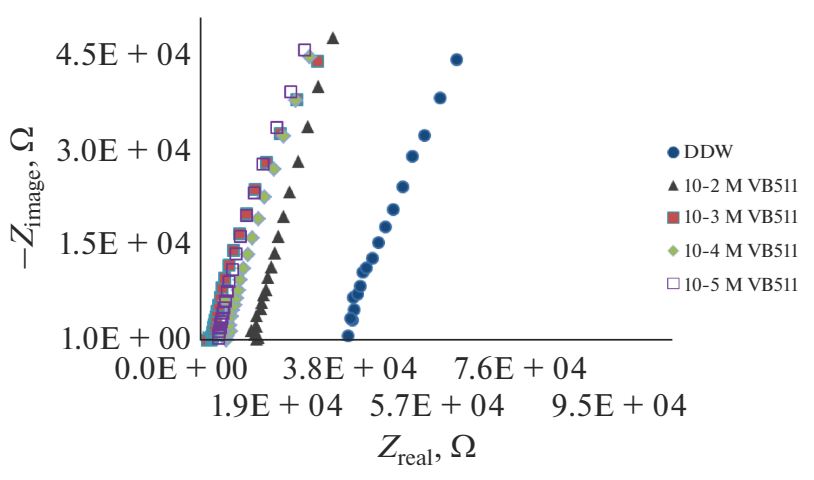

Fig. 2. Electrochemical plots of the AISI304 SS in DDW + $x$ M VB511 medium.

Table 2 for related diblock copolymers. The $\mathrm{pH}$ of the solutions was adjusted to 7.6 by using $0.01 \mathrm{M} \mathrm{NaOH}$ solution and a HANNA brand $\mathrm{pH}$ meter. The Tafel and Nyquist curves obtained for DDW $+x \mathrm{M}$ the VB511 are given in Fig. 2. As can be seen Table 2, we have used two class of polymers. One is the diblock copolymers having tertiaryamine residues on both blocks and the other one is PMMA block containing diblock copolymers.

The highest inhibition in the double distilled water (DDW) medium were observed with VB207 and VB511 polymers (Tables 3, 4; Fig. 2). The Higher molar mass of VB207 (Table 2) increased the inhibition of benzyl chloride in addition to the PDMA block. In VB511, the repetitive unit of PDMA was more effective in inhibition. The lowest inhibition in DDW occured in the VB201 and VB258 polymers (Table 3). The VB201 and VB258 had also the same PDMA-PMMA ratios, and similar molecular masses but their chain types are different (Table 2). As expected, diblock copolymers can self assemble into micellar form more easy than that of random copolymers. Thus, the adsorption of VB201 diblock copolymer on a metal surface might occur as micelles by interaction of PDMA chains/corona with the surface. In the case of PDMA-co-PMMA random copolymer, MMA residues may play a role in the adsorption of VB258 copolymer on metal surface as well. That was the point we observed. It is concluded diblock copolymer micelles (VB201) was less attached to the surface and prevented corrosion at that sort because of its diblock copolymer nature. It is concluded the adsorption of random copolymer was better than that of diblock copolymer. The steric effects on the surface, the VB201 was less attached to the surface and prevented corrosion at that sort because of the increased mass.

Interaction of the polymers with cathodic and anodic reactions delayed the oxidation and reduction of the corrosion reaction. It prevented water and active species from reaching the surface. The reaction of the cathodic plot is shown oxygen formation, the reaction of the anodic plot is shown dissolution of the iron in Tafel plots. The corrosion characteristics of DDW + xM diblock copolymers (Vb406, VB258, VB201, VB510, VB501, VB511) are given in Table 3.

Adsorption of the inhibitor affects corrosion in two ways:

i) The decrease of the present reaction area is called this geometric block effect;

ii) During the inhibition corrosion process, the inhibitor may modify the activation energy of anodic and /or cathodic reactions at the free metal surface.

It is difficult to determine from which of the inhibitor effect (the geometric block effect and the energy effect) originated. Theoretically, the geometric block effect is stronger than the energy effect if the $E_{\text {cor }}$ value does not shift after the inhibitor is added [12].

When examining $E_{\text {cor }}$ values (Table 3, Fig. 2) for the VB 501, VB 510 and VB 511, $E_{\text {cor }}$ shifted more than $85 \mathrm{mV}$ for the VB 501 and VB 510, but this difference decreased as the concentration increased. Therefore, VB 501, VB 510 and VB 511 exhibited mixed-type inhibitory properties when all concentrations were considered [13, 14].

For the VB 511, the $\beta_{\mathrm{a}}$ values at $10^{-5}$ and $10^{-3} \mathrm{M}$ concentrations were greater than the $\beta_{\mathrm{a}}$ values at all concentrations of VB 501 and VB 510 inhibitors. $\beta_{\mathrm{a}}$ values were increased with an increase in concentration of the inhibitor. Higher $\beta_{\mathrm{a}}$ values indicated that the rate of the anodic reduction reaction was slower. The inhibitor controlled the dissociation reaction of iron [15]. The anodic Tafel slope for the VB 511 at $10^{-5} \mathrm{M}$ concentration showed $\beta_{\mathrm{a}}=1.10^{18} \mathrm{mV} / \mathrm{dec}$, indicating that the anodic reaction was diffusion controlled.

When all four different diblock copolymer structures were examined, it was seen that DMA block was in different ratios at the VB511, VB 406, VB 201, and VB 258). There were 80 repeated DMA units in the VB 406 and 80 DMA in the VB 511. As shown in Table 3 as stated in, the increase of DMA block in the diblock copolymer is effective in inhibition. The DPA units in the VB 511 were 20 whereas the DEA units in the VB 406 were composed of 20 repetitive units. The DPA block in VB 511 structure was hydrophilic and more branched than DEA. The inhibition values of the VB 406 and VB 511 were very close to each other and the 
Table 3. The corrosion characteristics of DDW $+x$ M diblock copolymers (VB406, VB258, VB201, VB510, VB501, and VB511)

\begin{tabular}{|c|c|c|c|c|c|c|c|c|}
\hline & & $\begin{array}{c}\beta a, \\
\mathrm{mV} / \mathrm{dec} \text { ade }\end{array}$ & $\begin{array}{c}-\beta \mathrm{c} \\
\mathrm{mV} / \mathrm{dec} \text { ade }\end{array}$ & $\begin{array}{c}i_{\text {cor }} \\
\mathrm{nAcm}^{-2}\end{array}$ & $\begin{array}{c}E_{\mathrm{cor}}, \\
\mathrm{mV}\end{array}$ & $\begin{array}{c}\text { Corrosion rate } \\
\times 10^{3}, \mathrm{mpy}\end{array}$ & $\theta$ & $\%$ inh. \\
\hline \multicolumn{2}{|l|}{ DDW } & 41 & 813 & 1447 & -110 & 651 & - & - \\
\hline \multirow[t]{4}{*}{ +VB501 } & $10^{-5} \mathrm{M}$ & 810 & 190 & 188 & -297 & 84 & 0.87 & 87 \\
\hline & $10^{-4} \mathrm{M}$ & 503 & 302 & 385 & -196 & 173 & 0.73 & 73 \\
\hline & $10^{-3} \mathrm{M}$ & 379 & 143 & 266 & -166 & 120 & 0.82 & 82 \\
\hline & $10^{-2} \mathrm{M}$ & 303 & 146 & 172 & -163 & 77 & 0.88 & 88 \\
\hline \multirow[t]{4}{*}{ +VB510 } & $10^{-5} \mathrm{M}$ & 361 & 209 & 255 & -252 & 114 & 0.82 & 82 \\
\hline & $10^{-4} \mathrm{M}$ & 570 & 160 & 183 & -263 & 82 & 0.87 & 87 \\
\hline & $10^{-3} \mathrm{M}$ & 512 & 103 & 167 & -315 & 76 & 0.88 & 88 \\
\hline & $10^{-2} \mathrm{M}$ & 422 & 153 & 158 & -153 & 71 & 0.89 & 89 \\
\hline \multirow[t]{4}{*}{ +VB511 } & $10^{-5} \mathrm{M}$ & $1 \times 10^{18}$ & 237 & 377 & -191 & 169 & 0.74 & 74 \\
\hline & $10^{-4} \mathrm{M}$ & 534 & 334 & 367 & -152 & 165 & 0.75 & 75 \\
\hline & $10^{-3} \mathrm{M}$ & 1016 & 135 & 168 & -230 & 75 & 0.88 & 88 \\
\hline & $10^{-2} \mathrm{M}$ & 436 & 190 & 129 & -121 & 58 & 0.91 & 91 \\
\hline \multirow[t]{4}{*}{ +VB406 } & $10^{-5} \mathrm{M}$ & 615 & 228 & 245 & -261 & 110 & 0.83 & 83 \\
\hline & $10^{-4} \mathrm{M}$ & 309 & 198 & 203 & -182 & 91 & 0.86 & 86 \\
\hline & $10^{-3} \mathrm{M}$ & 276 & 147 & 185 & -211 & 83 & 0.87 & 87 \\
\hline & $10^{-2} \mathrm{M}$ & 217 & 178 & 165 & -220 & 74 & 0.89 & 89 \\
\hline \multirow[t]{4}{*}{ +VB201 } & $10^{-5} \mathrm{M}$ & 543 & 311 & 520 & -99 & 233 & 0.64 & 64 \\
\hline & $10^{-4} \mathrm{M}$ & 146 & 143 & 495 & -154 & 222 & 0.66 & 66 \\
\hline & $10^{-3} \mathrm{M}$ & 483 & 259 & 485 & -138 & 218 & 0.67 & 67 \\
\hline & $10^{-2} \mathrm{M}$ & 377 & 114 & 423 & -173 & 190 & 0.71 & 71 \\
\hline \multirow[t]{4}{*}{$+\mathrm{VB} 258$} & $10^{-5} \mathrm{M}$ & 679 & 193 & 596 & -181 & 230 & 0.59 & 59 \\
\hline & $10^{-4} \mathrm{M}$ & 132 & 277 & 713 & -174 & 320 & 0.51 & 51 \\
\hline & $10^{-3} \mathrm{M}$ & 482 & 308 & 530 & -170 & 238 & 0.63 & 63 \\
\hline & $10^{-2} \mathrm{M}$ & 344 & 123 & 390 & -163 & 176 & 0.73 & 73 \\
\hline
\end{tabular}

Table 4. The corrosion characteristics obtained for DDW $+x$ M diblock copolymers (VB206, VB207)

\begin{tabular}{l|c|c|c|c|c|c|c|c}
\hline \multicolumn{1}{c|}{$\mathrm{pH}=7.6$} & & $\begin{array}{c}\beta \mathrm{a}, \\
\mathrm{mV} / \mathrm{dec} \text { dede }\end{array}$ & $\begin{array}{c}-\beta \mathrm{c}, \\
\mathrm{mV} / \mathrm{dec} \text { ade }\end{array}$ & $\begin{array}{c}i_{\text {cor }}, \\
\mathrm{nA} \mathrm{cm}{ }^{-2}\end{array}$ & $\begin{array}{c}E_{\text {cor }} \\
\mathrm{mV}\end{array}$ & $\begin{array}{c}\text { Corrosion } \\
\text { rate } \times 10^{3}, \mathrm{mpy}\end{array}$ & $\theta$ & $\%$ inh. \\
\hline DDW & & 41 & 813 & 1447 & -110 & 651 & - & - \\
$+\mathrm{VB} 206$ & $10^{-5} \mathrm{M}$ & 147 & 139 & 367 & -196 & 164 & 0.75 & 75 \\
& $10^{-4} \mathrm{M}$ & 2427 & 277 & 341 & -133 & 153 & 0.76 & 76 \\
& $10^{-3} \mathrm{M}$ & $1 \times 10^{18}$ & 231 & 321 & -96 & 142 & 0.78 & 78 \\
& $10^{-2} \mathrm{M}$ & 3415 & 253 & 204 & -109 & 91.4 & 0.86 & 86 \\
$+\mathrm{VB} 207$ & $10^{-5} \mathrm{M}$ & $818 \times 10^{9}$ & 457 & 846 & -87 & 380 & 0.42 & 42 \\
& $10^{-4} \mathrm{M}$ & 234 & 192 & 199 & -119 & 86 & 0.86 & 86 \\
& $10^{-3} \mathrm{M}$ & 175 & 140 & 178 & -125 & 82 & 0.88 & 88 \\
& $10^{-2} \mathrm{M}$ & 587 & 182 & 114 & -117 & 51 & 0.92 & 92 \\
\hline
\end{tabular}

PROTECTION OF METALS AND PHYSICAL CHEMISTRY OF SURFACES 
Table 5. Thermodynamic adsorption parameters of polymers obtained by Tafel extrapolation in double distilled water media

\begin{tabular}{l|c|c}
\hline \multicolumn{1}{c|}{ Inhibitor } & $K_{\mathrm{ads}}, \mathrm{dm}^{3} \mathrm{~mol}^{-1}$ & $\Delta G_{\mathrm{ads},} \mathrm{kJ} \mathrm{mol}^{-1}$ \\
\hline VB 201 & 2.893 & -12.455 \\
VB 258 & 7.058 & -14.643 \\
VB 206 & 8.373 & -15.062 \\
VB 406 & 11.117 & -15.757 \\
VB 510 & 12.308 & -16.006 \\
VB 511 & 25.960 & -17.837 \\
VB 501 & 20.040 & -17.202 \\
VB 207 & 85.389 & -20.757 \\
\hline
\end{tabular}

inhibition values of VB 511 were similar to those of the VB 406 except that only two groups of methyl groups were similar in VB 406. The VB 511, VB 406, VB 201 and VB 258 showed a mixed-type inhibitor properties $[16,17]$. Each of four diblock copolymers formed a micellar structure when dissolved in water. While the DEA block in the VB 406, the DPA block in the VB 511, and the MMA block in the VB 201 and VB 258 formed the mycella core. PDMA blocks form the coronas of the micelles.

The presence of the DPA monomer in VB 511 and the presence of the DEA monomer in VB 406 maked the difference at inhibition. DEA differs from DPA in which only two methyl groups are involved. Because of less hydrophilic nature of the methyl groups in the structure of PDPA, VB 511 was more adsorbed on the surface of the metal and increased the inhibition. $\mathrm{E}_{\text {cor }}$ values for VB 511 showed a mixed inhibitor property due to the shift at more negative potentials. $\beta a$ values indicated that the corrosion reaction was diffusion controlled. The unchanged value of $\beta \mathrm{c}$ (metal dissolution and reduction reaction of oxygen /water ) showed that the reactions were slower down. VB 511 polymer reduced the corrosion rate without altering the mechanism. For example, adsorbed molecules mechanically covered a portion of the electrode and thus protected it from the attack of the corrosive environment [18].

As the concentration of VB 406 in the solution was increased (Table 3), because of the slopes of the vertical $\beta_{\mathrm{a}}$ and $\beta_{\mathrm{c}}$ values, the corrosion rate was decreased. VB406 polymer showed a mixed-type inhibitor 1 behaviour [17, 19, 20].

In VB201 and VB258, the rates of DMA recurring units were also same (80) (Table 2). As a result of this, the inhibitions were also very close to each other. VB258 showed $73 \%$ inhibition at $10^{-2} \mathrm{M}$ concentration while VB201 showed $71 \%$ inhibition at $10^{-2} \mathrm{M}$ concentration (Table 3). In VB258, the same increased in the repetition rate of MMA and the same decrease in DMA caused this (Table 2). In VB511 and VB406, the inhibition of different - R groups following the same nitrogen to chain lengths up to the nitrogen unit also played a role. Parallel and cathodic Tafel curves showed that the oxygen /water reduction was activation controlled and the reduction mechanism was not affected by the presence of the inhibitor. Protonated molecules are adsorbed onto the cathodic sites. Neutral molecules are adsorbed onto anodic sites. Thus, both processes are inhibited. Polymers that have heteroatoms and active sites can be used as adsorption inhibitors. Polymers can be adsorbed on the metal surface to control anodic and cathodic reactions during the corrosion process. Corrosion inhibiting activities are directly proportional to the amount of inhibitor adsorbed. The functional groups and structure of the inhibitor play an important role in the adsorption process [21-23]. On the other hand, electron transfer takes place during the adsorption of neutral organic compounds on the metal surface [24].

PMMA based copolymers (VB 201 and VB 258) were not effective to prevent corrosion very much as compared to the polymers having DEA and DPA units. Increasing DMA units in the copolymer inhibitors have also been effectived. Given the adsorption properties (Table 5), the $\Delta \mathrm{G}$ values indicated that the adsorption was physical adsorption. Isotherms fitted the Langmuir adsorption equation [24-26].

DMA is an interesting hydrophilic monomer in the textile sector, due to potential applications such as pigment dispersions, hydrogels and synthetic vectors in DNA complexation. PDMA homopolymer is soluble in water as a weak cationic polyelectrolyte $\left(p K_{\mathrm{a}}=7.0 \pm 0.5\right)$ due to the protonation of tertiary amine groups to low $\mathrm{pH}$. The solubility of this polymer in water is only provided by the hydrogen bond [27, 28].

The PDMA blocks in the PDMA- $b$-PDEA diblock copolymer can be quaternized fully and selectively as long as a stoichiometric amount of alkyl halide (such as methyl iodide) is used under mild conditions [28].

While VB 201 is a hydrophilic and hydrophobic diblock copolymer. VB258 is a random copolymer having the same comonomers with VB201. Soluble hydrophilic and hydrophobic diblock copolymers can be dissolved directly in aqueous media surfactant.

Poly[2-(dimethylamino)ethylmethacrylate]- $b$-poly[methylmethacrylate] diblock copolymers (PDMA- $b$ PMMA) have been used as steric stabilizers in the synthesis of charged latexes of smaller sizes than micrometres used in the preparation of oil-in water systems [29]. PDMA- $b$-PMMA diblock copolymers can be synthesized by group transfer polymerization (GTP) with very good control of molar weight and comonomer ratio. In the PDMA- $b$-PMMA diblock copolymer used for the preparation of oil in water systems, the PMMA block adsorbs to the latex surface while the PDMA block dissolved in the medium acts as a steric stabilizer, and colloidal stability is obtained. Here, the hydrophilic character of the PDMA- $b$ PMMA is provided by the control of the solution $\mathrm{pH}$. The corrosion characteristics obtained for DDW $+x \mathrm{M}$ 
diblock copolymers (VB206, VB207) are given in Table 4.

The inhibition values calculated for VB201 and VB258 in Table 3 were compared with the inhibition values for VB206 and VB207 given in Table 4. In VB201, VB206 and VB207 diblock copolymers the MMA recurring units were 20 (Table 2).

The $\beta$-DMA structure in the VB206 also affected the inhibition. In VB207, quaternization of the DMA block with benzyl chloride is highly effective in inhibition. The VB207 showed the best inhibition in all diblock copolymers. The all diblock copolymers having DMA structure played important role the inhibition. MMA had not much effect on inhibition. These polymers blocked the active surface sites and reduced the corrosion rate. At the metal solution interface, four types of adsorption can occur by organic inhibitors.

i) Electrostatic interaction between charged molecules and charged metal;

ii) Interaction between metal and $p$ electrons;

iii) Interaction between metal and uncharged electron pairs;

iv) $i$ and iii are occured at the same time.

Anodic current increases at higher anodic overvolt1 ages. This behaviour may be due to severe dissolution of the iron. Corrosion products cause breakage of the layer and cause inhibitor film in desorption from the metal surface. In this case the desorption rate of the inhibitor is higher than the adsorption rate [16].

\subsection{Thermodynamic Adsorption Results and Discussions}

Khaled and Hackerman [30] reported that; the adsorption process depends on the physical and chemical properties of the inhibitor molecule. The electron density of these donor atoms and possible steric effects are also dependent on the nature of the adsorbed metal surface, the chemical composition of the corrosive medium, the reaction temperature, and the electrochemical potential at the metal solution interface [ 16 , $21,23,31]$.

It is generally accepted that the adsorption of inhibitors on the metal surface is the necessary step in the inhibition mechanism and the adsorption isotherm is the most appropriate way to characterize the metal/inhibitor/environment system. The formation of isotherms that define the adsorptive behavior of inhibitors is important to investigate the nature of the metal-inhibitor interaction. $\mathrm{K}_{\mathrm{ads}}$ values can be taken as a measure of the strength of adsorption forces between inhibitor molecules and the metal surface [32].

Adsorption and desorption rate ratio can be written as Eq. (2):

$$
\frac{1}{1-\theta}=\frac{k_{\mathrm{a}}}{k_{\mathrm{d}}}\left(e^{-\frac{\Delta G_{\mathrm{ads}}}{R T}}\right) c .
$$

In this equation, the adsorption and desorption rate constants $\left(k_{\mathrm{a}}\right.$ and $\left.k_{\mathrm{d}}\right)$ and the adsorption-free energy $\left(\Delta G_{\text {ads }}\right)$ relationship represent adsorption equilibrium constant $\left(K_{\text {ads }}\right)$

$$
\frac{1}{1-\theta}=K_{\mathrm{ads}} c .
$$

Between the adsorption equilibrium constant in the isotherm equations, $K_{\text {ads }}$, adsorption free energy change, $\Delta G_{\mathrm{ads}}$, is a relationship as shown in the following equation:

$$
K_{\text {ads }}=\left(\frac{1}{55.5}\right) \mathrm{e}^{-\Delta G_{\text {ads }} / R T} .
$$

The value of 55.5 in equation 4 is the number of moles of one $\mathrm{m}^{3}$ of water. $R$ is the ideal gas constant and the value is 8.314 joule mole ${ }^{-1} \mathrm{~K}^{-1}$. It is suggested that the surface covering ratio $(\theta)$ is the bond between the metal atoms and the inhibitor molecules. The surface coverage fraction is a function of the electronic density on the functional atoms of the organic inhibitors. The molecules may be adsorbed, between adsorbed at the metal/solution interface by formation of either electrostatic or covalent bonds and metal surface atoms. The surface coverage fraction is useful in determining inhibitor adsorption characteristics.

The inhibition of corrosion of organic compounds is due to their ability to adsorb by forming a protective film. The adsorption of organic inhibitors at the metal solution interface is due to the displacement of water molecules and organic molecules with respect to the following reaction $[9,11,12,15,16,21,33-36]$.

$\mathrm{Org}(\mathrm{sol})+x \mathrm{H}_{2} \mathrm{O}(\mathrm{ads}) \rightarrow \mathrm{Org}(\mathrm{ads})+x \mathrm{H}_{2} \mathrm{O}(\mathrm{sol})$. (5)

The terms Org (sol) and Org (ads) in this equation show organic molecules adsorbed on the surface and in the solution, respectively. $x$ is the number of water molecules displaced by organic molecules.

Knowing the kind of adsorption and isotherm gives important information about the interaction of the inhibitor and the metal surface. The high values of $K_{\text {ads }}$ and negative values of $\Delta G_{\text {ads }}$ show strong adsorption of the inhibitor on the steel surface. Generally, $\Delta G_{\text {ads }}$ values are $-20 \mathrm{~kJ} \mathrm{~mol}^{-1}$, indicating the electrostatic interactions between charged molecules and charged metal (physical adsorption) [10, 25, 37]. If $\Delta G_{\text {ads }}$ values are more negative than $-40 \mathrm{~kJ} \mathrm{~mol}^{-1}$, they involve the transfer or sharing of electrons (chemisorption) with coordinated-type covalent bond formation from the inhibitor molecules to the metal surface [15, 32, 33, 38].

The Langmuir adsorption isotherms obtained from DDW $+x \mathrm{M}$ copolymer (VB207, VB510) media are given in Fig. 3.

When looking at Fig. 3, the point at which the ordinate is cut for VB207 has the highest value in the log $K_{\text {ads }}$ value isotherm right curve. VB207 polymer showed the highest inhibition in the DDW environ- 

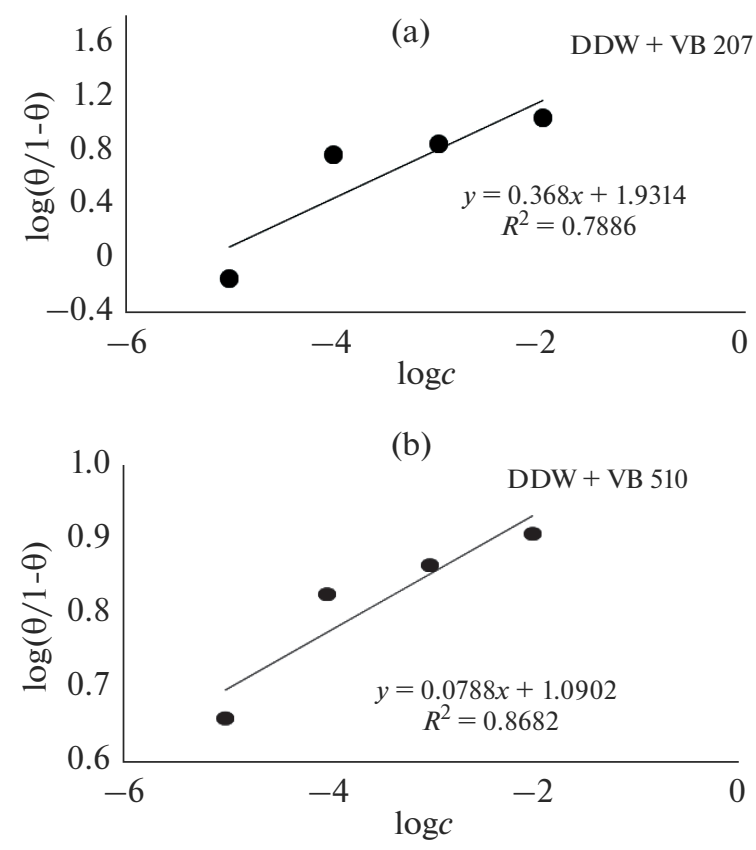

Fig. 3. The Langmuir adsorption isotherms obtained from DDW $+x$ M copolymer (VB207, VB510) media.

ment. VB511, VB501 and VB510 polymers followed the VB207. All polymers conformed to the Langmuir adsorption equation and gave a correct line. The VB201 polymer showed the worst inhibition.

The adsorption depends on the charge and nature of the metal, the electronic characteristics of the metal surface, the adsorption of the solvent and other ionic species, the temperature of the corrosion reaction and the electrochemical potential at the solution interface. The interaction responsible for the binding of the inhibitor on the metal surface involves two types of formation: The first (physical adsorption) interaction consists of two weakly undirectional interactions and the electrostatic interactions between the inhibitor and the organic surface of the metal ions or dipoles metal.

Zero-charge potential plays an important role in the electrostatic adsorption process. The load on the metal surface can be explained in terms of potential difference $(F)$ between corrosion potential $\left(E_{\text {cor }}\right)$ and zero load potential $\left(E_{\mathrm{pzc}}\right)$. If $\mathrm{F}$ is negative, adsorption of cations is preferred. The second type of interaction (adsorption) is the interaction between the adsorbent and the adsorbent directly by the directed forces. Chemical adsorption involves charge transfer to the metal surface atoms of the adsorbent to form a chargesharing or coordinated covalent bond. Chemical adsorption has higher activation energy than adsorption free energy and physical adsorption. It is usually irreversible. Adsorption isotherms are generally used to describe the adsorption process.

Forming of adsorption isotherms in the identification of a corrosion inhibitor may provide important clues as to the nature of the metal inhibitor interaction. The adsorption of organic molecules occurs when the interaction energy between the metal surface and the molecule is greater between water and the metal surface [24].

When the $K_{\text {ads }}$ values are examined in Table 5 , the diblock copolymers adsorb on the AISI 304 steel surface themselves. The $\Delta G_{\text {ads }}$ values confirm this. According to the percentage inhibition values in Tables 3 and $4, K_{\text {ads }}$ and $\Delta G_{\text {ads }}$ values are in agreement with each other. As we noted in our previous comments, as the number of DMA repeat units increases, the inhibition, $K_{\text {ads }}$ and $\Delta G_{\text {ads }}$ values are also increasing. Especially in diblock copolymers, if the degree of polymerisation of PDMA blocksis above 79, the inhibition values are above $88 \%$ in double distilled water.

However, the highest inhibition in all diblock copolymers showed the inhibition of VB207 BzPDMA- $b$-PMMA diblock copolymer in DDW, at the $\mathrm{pH}=7.6$. Gibbs energy had also the second highest value $-20.715 \mathrm{~kJ} \mathrm{~mol}^{-1}$ MMA containing. VB201, VB258 and VB406 diblock copolymers have the same comonomer ratio $\left[(\mathrm{DMA})_{80}-(\mathrm{MMA})_{20}\right]$ (Table 2). The $\Delta G_{\text {ads }}$ value of VB206 was larger and more negative because of the betaine structure. This shows that VB206 had a higher surface coverage (0.86) than VB201. As the surface coverage increased, the $\Delta G_{\text {ads }}$ value also increased.

In VB510, VB511 and VB501, as the degree of polymerisation of PDMA blocks increased, the surface coverage fraction increased. It is understood that, having both PDMA and PDPA in the structure of VB501 provided the highest of $K_{\text {ads }}$ and $\Delta G_{\text {ads }}$ values. The optimal repeating units in diblock colpolymer for physical adsorption were 70 DMA and 30 DPA, respectively. The PDMA homopolymer had a coating fraction of 0.91 in the monobloc structure and was close to the highest $\Delta G_{\text {ads }}$. This shows that PDMA was more adsorbed on the surface and prevented corrosion.

\subsection{ICP-OES Analyses Results and Discussions}

The element analysis of the AISI 304 stainless steel was done using Spectro Genesis Fee model Plasma Optical Emission Spectrometry (ICP-OES). For elemental analysis, samples were kept for 7 days in DDW + $10^{-2} \mathrm{M}$ polymer solutions $(\mathrm{Cr}, \mathrm{Cu}, \mathrm{Mn}, \mathrm{Fe}, \mathrm{Ni})$. The ICP-OES analyses are given in Table 6. It is seen in Table 6 that the more dissolution of iron are $38.3 \mathrm{mgL}^{-1}$ at $\mathrm{pH} 7.6$ in double-distilled media for VB501 polymer.

\subsection{SEM-EDX Analyses Results and Discussions}

The polymers showed the best inhibition at $10^{-2} \mathrm{M}$ concentration. For this reason, $10^{-2} \mathrm{M}$ concentrated 
solutions (DDW) were prepared. One surface of the AISI 304 stainless steel electrodes polished (the other surfaces of electrodes coated with epoxy resin) was put in the brown glass bottles of $100 \mathrm{~mL}$ volume. Moreover, $20 \mathrm{~mL}$ of $10^{-2} \mathrm{M}$ concentrated polymer solution was added into the bottle. The mouths of the bottles were closed and waited for one week in a water bath at $22^{\circ} \mathrm{C}$. After one week the electrodes were removed from the polymer solution and surfaces were analysed LEO 1430 VP microscope was used to get images. Furthermore, EDX analyses (having Quantax soft program Röntec EDX device attached to SEM microscope ) were also carried out on these samples. SEM images of the AISI 304 SS kept for a week in DDW + $10^{-2} \mathrm{M}$ polymer solution (VB501, VB510, VB511, VB 207,VB201, VB258, VB406, VB206) are also given in Fig. 4 and EDX atomic values are given in Fig. 5.

In the absence of inhibitor (Fig. 4a), the surface is highly damaged and there is a smoother surface in the presence of inhibitor (Fig. 4). The molecules of the inhibitors forming a protective film on the steel surface decreased the dissolution of metal [33].

The percentage inhibition values of VB510, VB511 and VB501 were very close to each other (Fig. 4, Table 3). The black dots (Fig. 4e) that appear on the metal surface in the DDW + VB511 medium may be cast point defects resulting from faults during the casting of the steel. These defects were seen in the VB501 (Fig. 4c) and VB510 medium (Fig. 4d). The metal surfaces were more homogeneous and uniform. Only sanding errors were visible.

In Table 2, the increase in the DMA repeat unit in the structure of the VB511 is effective on corrosion. $\mathrm{Cr}$ amount on the metal surface in the VB511 solution increased. EDX analysis (Fig. 5) caused the formation of protective chromium oxides on the surface (VB501 and VB510). This was effective in inhibition.

The branched structure of the DPA block in the VB511 (Fig. 1) and the DMA having a low repetition rate were effective in covering the steel surface and preventing corrosion.

When EDX analyses (Fig. 5) were examined, it was detected that the amount of $\mathrm{Cr}$ and $\mathrm{Ni}$ on the steel surface increased in the VB511 medium than the other polymers. This is the explanation why the VB511 showed high corrosion inhibition.

In Fig. 4b, the SEM image of the metal surface in DDW $+10^{-2} \mathrm{M}$ VB207 medium is fairly homogenous. There is no corrosion on the surface. VB207 was a diblock copolymer which exhibits the best inhibition when compared to all other polymers in the DDW environment.

Examining Table 5 (VB501, VB511, and VB510 compared among themselves) it appears that the VB511 has the highest $\Delta G_{\text {ads }}$ value. As noted in Tafel's comment, the increased DMA ratio of inhibitor struc-
Table 6. ICP-OES solution analyses

\begin{tabular}{l|c|c|c|c}
\hline Inhibitor & $\mathrm{Cu}, \mathrm{mgL}^{-1}$ & $\mathrm{Fe}, \mathrm{mgL}^{-1}$ & $\mathrm{Ni}, \mathrm{mgL}^{-1}$ & $\mathrm{Mn}, \mathrm{mgL}^{-1}$ \\
\hline DDW & 0.039 & 0.031 & - & 0.038 \\
VB 201 & 8.628 & 6.873 & - & 20.150 \\
VB 258 & 4.263 & - & - & 23.288 \\
VB 206 & - & 3.966 & - & 36.817 \\
VB207 & 0.078 & 0.036 & - & 0.004 \\
VB 406 & - & 7.298 & - & 22.058 \\
VB 510 & 17.996 & 5.436 & - & 12.305 \\
VB 511 & - & 4.613 & - & 19.783 \\
VB 501 & 15.090 & 38.317 & 77.776 & 20.122 \\
\hline
\end{tabular}

- is not determined

ture and has been effective in making the of the steel surface homogeneous and uniform.

SEM image (Fig. 4i) in VB406 solution was found less noticeable embrittlement and casting error traces. The sanding traces of the AISI 304 SS surface were more pronounced in DDW $+10^{-2} \mathrm{M}$ the VB201 and VB258 solution (Fig. 4f-h). The branching in the second diblock copolymer methyl methacrylic acid structure in the VB201 and VB258 was very small (Fig. 1). $\backslash$ The methyl methacrylate block was at $\mathrm{pH}=7.6$. Although it was not effective in preventing corrosion, it improved acidity on the steel surface. The SEM image of the AISI 304 SS surface in DDW $+10^{-2} \mathrm{M}$ the VB206 solution (Fig. 4g) was quite different from the others. The surface was made up of geometric structures. In double distilled water environment, VB206 had the closest inhibition value to VB207. The AISI 304 SS surface has sulfur and carbon unlike the other EDX spectrum of Fig. 5. The highest amount of oxygen of metal surface was also in DDW $+10^{-2} \mathrm{M}$ VB406 (Fig. 5). This is why the surface is different from the other VB406, VB 201 and VB 258 polymer mediums.

When polymers were compared to each other (VB201, VB258, VB206, and VB207), VB207 showed the best inhibition in DDW $+10^{-2} \mathrm{M}$ polymer concentration. VB201 diblock copolymer and VB258 random copolymer, VB206 3 PDMA-PMMA were all effective in inhibition (Fig. 1).

The SEM image of the steel surface in DDW + $10^{-2}$ M VB206 (Fig. 4g) appeared to be quite different from the others. At $50 \times$ magnification, rods and peaks were found on the surface. The point analysis values of both were the same. In EDX analysis, it can be considered that $\mathrm{C}$ and $\mathrm{O}$ were on the metal surface, and they protected the surface from corrosion. The EDX analyses of in DDW $+10^{-2} \mathrm{M}$ VB201 and VB258 showed the same inhibition results as atomic \% values (Fig. $4 \mathrm{f}-\mathrm{h}$ ).

VB201 and VB258 had almost the same PDMA- $b$ PMMA ratios (Fig. 1). In VB206 the methyl or other 
(a)
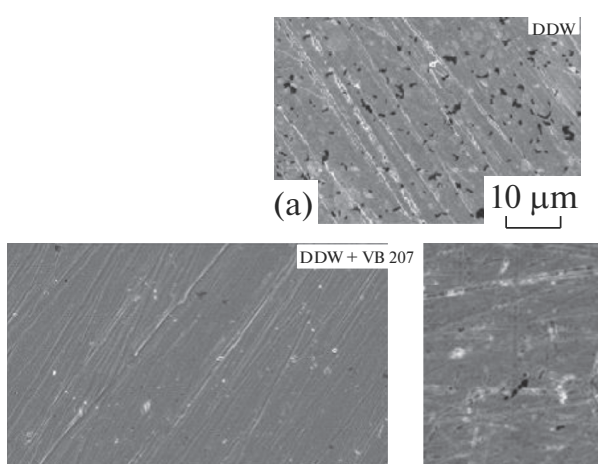

(b)

$10 \mu \mathrm{m}$

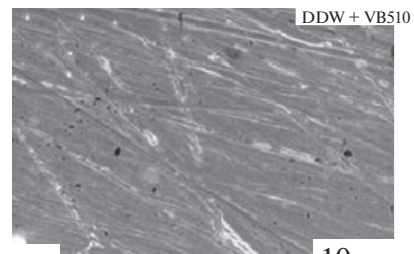

(d)

$10 \mu \mathrm{m}$

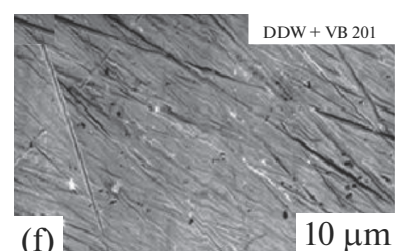

(f) $\mathrm{N}$ $10 \mu \mathrm{m}$

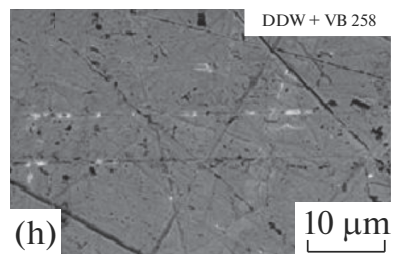

(h)

$10 \mu \mathrm{m}$
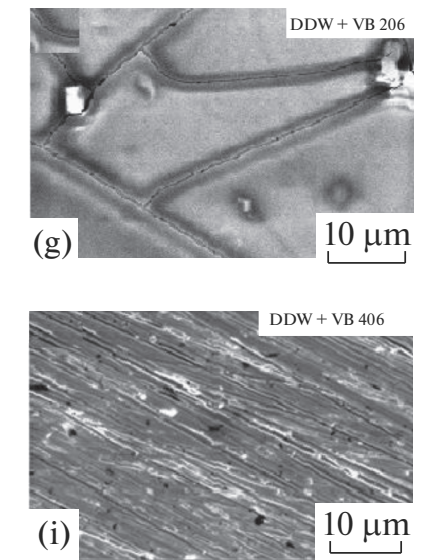

Fig. 4. SEM images of the AISI 304 SS kept for one week in DDW $+10^{-2} \mathrm{M}$ polymer solution (VB501, VB510, VB511, VB 207, VB406, VB251, VB258, and VB206).

group attached to the carbon in the DMA group was displaced. Although VB206 had the same PDMA- $b$ PMMA ratio as the VB201, the $\beta$ structure resulting from binding to the carbon group in DMA increased the inhibition by $15 \%$.

The highest inhibition concentration at VB201 (Table 3) was $71 \%$ at $10^{-2} \mathrm{M}$ concentration, while the lowest inhibition at VB206 was $75 \%$ at $10^{-5} \mathrm{M}$ concentration (Table 4). The $\beta$ structure in VB206 increased the inhibition.

\subsection{AFM Analyses Results and Discussions}

The corrosion inhibiting properties of the inhibitors were the result of the barrier effect of the polymer coated layer on mild steel surfaces. Acrylic polymers are the best possible organic coating material and the

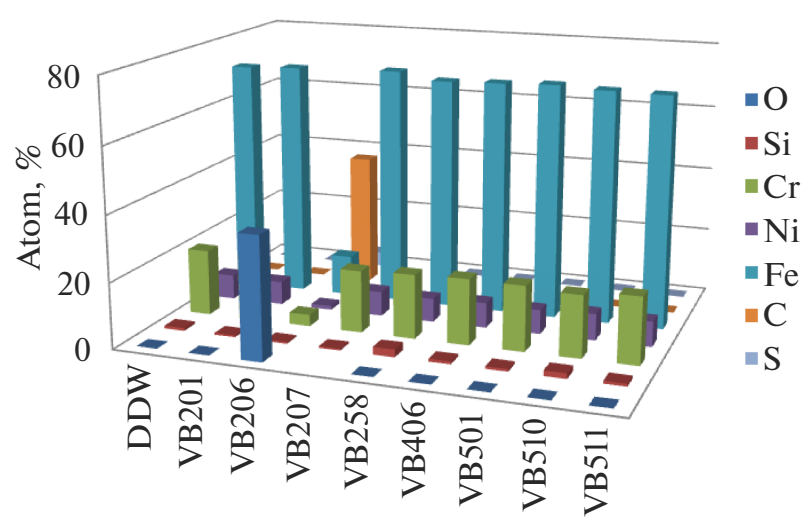

Fig. 5. EDX atomic \% values of AISI 304 SS surface which were left in the DDW and DDW $+10^{-2} \mathrm{M}$ polymer medium for a week.

mechanism for the effectiveness of the copolymers depends on their structure.

In Fig. $6 \mathrm{~b}$ the surface depth is between $-100 \mathrm{~nm}$ and $+100 \mathrm{~nm}$. Abrasive paper marks are more intense. The inhibitor film thickness is around $100 \mathrm{~nm}$. This film thickness is sufficient to prevent corrosion. The presence of this film on the surface indicates that the inhibitor is adsorbed to the surface. The highest inhibition in the DDW environment was observed with VB207 polymer.

Organic polymer coatings play an important role in protecting metals in many environments. Metacrylic polymers can be considered as one of the best organic coating materials nowadays. The Nyquist spectrum for uncoated steel is a semicircular shape. Due to, for example, metal corrosion, which shows the analysis process of the system, the charge transfer resistance and the double layer capacity of the liquid surface interface are due to the heterogeneity of the deviation surface printed within the Nyquist curves. Printed semicircular and indentive loops are caused by nonhomogeneous surfaces on the active sites, and surface loosening is accounted for. Further examples are under many redox processes with multiple time constants leading to the center of the semicircles under the real axis. This behavior is related to iron dissolution and ion diffusion. The ion charge is due to transfer. With an increase in the concentration of inhibitor rot is reduced. Coll is also decreases. The tendency to decrease in coll may be due to a decrease in the local dielectric constant or an increase in the thickness of the double layer increases [39].

The prevention of corrosion by very thin organic polymer coatings are striking considering that Funke et al., indicated that organic coatings protect metals from corrosion of as physico-chemical, electrochemically and structurally. Metacrylic polymer coatings among organic coatings have a wide range of application in various industries [39]. 
(a)

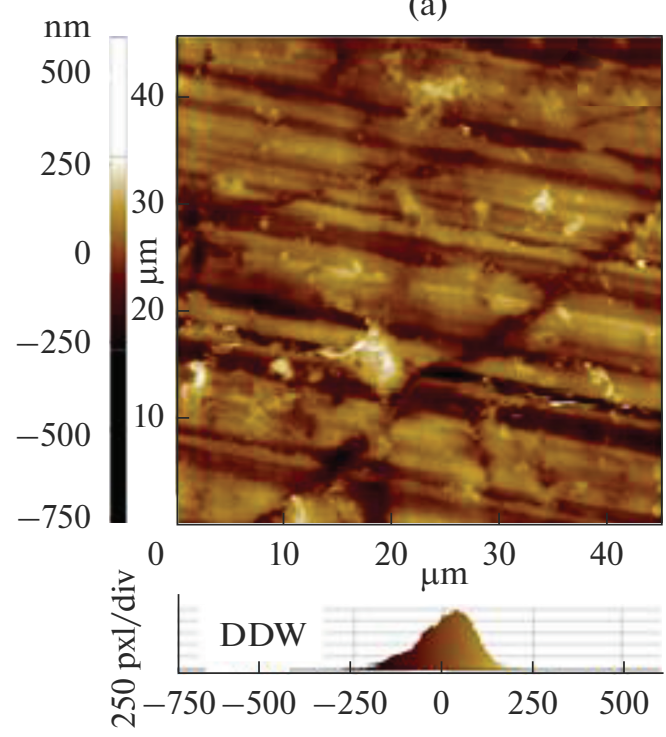

(b)

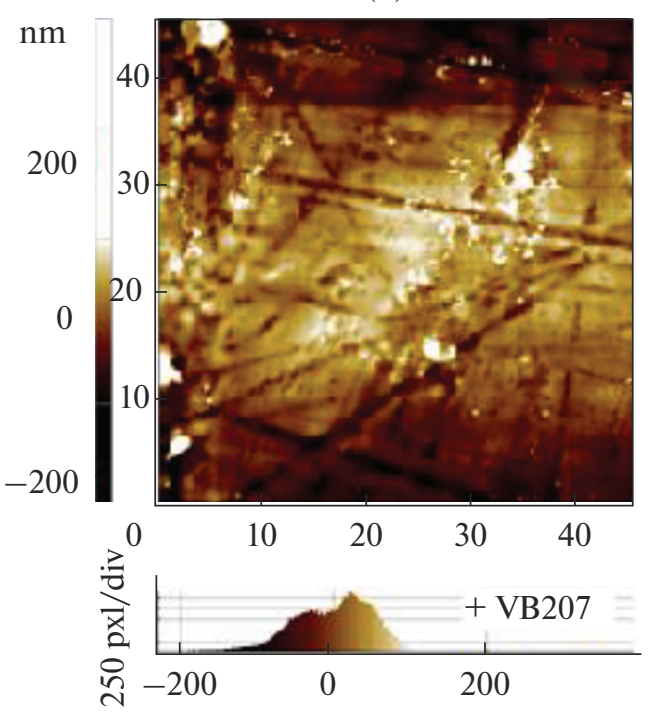

Fig. 6. AFM images of the AISI304 after being waited for a week in DDW and DDW $+10^{-2} \mathrm{M}$ VB207 polymer solution.

\section{CONCLUSIONS}

1. The presence of a DMA and MMA group in the polymer structure increased the inhibition.

2. The best inhibition in the double distilled water environment was seen with a cationic VB207 diblock copolymer. erty.

3. Polymers showed a mixed type inhibitor prop-

4. Both betainization and quaternizationnof PDMA block had a great effect on their inhibition properties

5. Physical adsorption was made on AISI 304 stainless steel surface.

6. Polymers conformed to isotherm curves of the Langmuir adsorption equation.

7. SEM-EDX analyses showed that the steel surface was not uniform in the absence of inhibitor, and that the steel surface in the presence of the inhibitor was smoother and homogenous. This showed that inhibitor molecules inhibited the dissolution of steel by forming a protective film on the steel surface.

\section{REFERENCES}

1. Anderson, B.C. and Mallapragada, S.K., Biomaterials, 2002, vol. 23, p. 4345.

2. Bütün, V, Armes, S.P., Billingham, N.C., Polymer, 2001, vol. 42, p. 5993.

3. Bütün, V, Armes, S.P., Billingham, N.C., Macromolecules, 2001, vol. 34, p. 1148.

4. Yurt, A, Bütün, V., and Duran, B., Mater. Chem. Phys., 2007, vol. 105, p. 114.

5. Arslan, H., Zırtıl, O., and Bütün, V., Eur. Polym. J., 2013, vol. 49, p. 4118 .
6. Ali, Sk.A. and Saeed, M.T., Polymer, 2001, vol. 42, p. 2785.

7. Bütün, V., Polymer, 2003, vol. 44, p. 7321.

8. Bütün, V., Sonmez, S., Yarligan, S., Taktak, F.F., Atay, A., and Butun, S., Polymer, 2008, vol. 49, p. 4057.

9. Allam, N.K., Appl. Surf. Sci., 2007, vol. 253, p. 4570.

10. Odob, I.B., Ebenso, E.E., and Kabanda, M.M., J. Environ. Chem. Eng., 2013, vol. 1, p. 431.

11. Solmaz, R., Altunbaş, E., and Kardaş, G., Mater. Chem. Phys., 2011, vol. 125, p. 796.

12. Javadian, S., Yousefi, A., and Neshati, J., Appl. Surf. Sci., 2013. vol. 285, p. 674.

13. Riggs, O.L., US Patent 3061553, 1962.

14. Ferreira, E.S., Giacomelli, C., Giacomelli, F.C., and Spinelli, A., Sci. Direct, 2004, vol. 83, p. 129.

15. Hegazy, M.A., Badawi, A.M., Abd El Rehim, S.S., and Kamel, W.M., Corros. Sci., 2013, vol. 69, p. 110.

16. Zadeh, A.R.H., Danaee, I., and Maddahy, M.D., J. Mater. Sci. Technol., 2013, vol. 29, no. 9, p. 884.

17. Karthikaiselvi, R. and Subhashini, S., Arabian J. Chem., 2012. http://dx.doi.org/. Karthikaiselvi, R. and Subhashini, S., Arabian J. Chem., 2017, vol. 10, no. 1, Suppl., p. S627. https://doi.org/10.1016/j.arabjc.2012.10.024

18. Moussa, M., El-Far, A., and El-Shafei, A., Sci. Direct, 2007, vol. 105, p. 105.

19. Özkır, D., Kayakırılmaz, K., Bayol, E., Gurten, A.A., and Kandemirli, F., Corros. Sci., 2013, vol. 56, p. 143.

20. Desimone, M.P., Gordillo, G., and Simison, S.N., Corros. Sci., 2011, vol. 53, p. 4033.

21. Zhang, Q., Gao, Z., Xu, F., and Zou, X., Colloids Surf., A, 2011, p. 380, p. 191.

22. Herrag, L., Hammouti, B., Elkadiri, S., Aouniti, A., Jama, C., Vezin, H., and Bentiss, F., Corros. Sci., 2010, vol. 52 , p. 3042 . 
23. Bahrami, M.J., Hosseini, S.M.A., and Pilvar, P., Corros. Sci., 2010, vol. 52, p. 2793.

24. Singh, A.K., Shukla, S.K., Quraishi, M.A., and Ebenso, E.E., J. Taiwan Inst. Chem. Eng., 2012, vol. 43, p. 463.

25. Srimathi, M., Rajalakshmi, R. and Subhashini, S., Arabian J. Chem., 2010. vol. 7, p. 647.

26. Ahamad, I. and Quraishi, M.A., Corros. Sci., 2009, vol. 51, p. 2006

27. Bütün, V., Billingham, N.C., and Armes, S.P., Chem. Commun., 1997, vol. 7, p. 671. https://doi.org/10.1039/A700772H

28. Bütün, V., Lowe, A.B., Billingham, N.C., and Armes, S.P., J. Am. Chem. Soc., 1999, vol. 121, p. 4288.

29. Amalvy, J.I., Wanless, E.J., Li, Y., Michailidou, V., Armes, S.P., and Duccini, Y., Langmuir, 2004, vol. 20, p. 8992.

30. Khaled, K.F. and Hackerman, N., Electrochim. Acta, 2003, vol. 48, p. 2715.
31. Daoud, D., Douadi, T., Issaadi, S., and Chafaa, S., Corros. Sci., 2014, vol. 79, p. 50.

32. Liu, B., Xi, H., Li, Z., and Xia, Q., Appl. Surf. Sci., 2012, vol. 258, p. 6679.

33. Farag, A.A. and El-Din, M.R.E., Corros. Sci., 2012, vol. 64, p. 174.

34. El-Latef, H.M.A., Abbasov, V.M., Aliyeva, L.I., Qasimov, E.E. and Ismayilov, I.T., Mater. Chem. Phys., 2013, vol. 142, p. 502.

35. Fouda, A.S. and Ellithy, A.S., Corros. Sci., 2009, vol. 51, p. 868.

36. Azghandi, M.V., Davoodi, A., Farzi, G., and Kosari, A., Corros. Sci., 2012, vol. 64, p. 44.

37. Atta, A.M., El-Azabawy, O.E., Ismail, H.S., and Hegazy, M.A., Corros. Sci., 2011, vol. 53, p. 1680.

38. Liu, B., Liu, Z., Han, G., and Li, Y., Thin Solid Films, 2011, vol. 519, p. 7836.

39. Srikanth, A.P., Lavanya, A., Nanjundan, S., andRajendran, N., Sci. Direct, 2006, vol. 253, p. 1810.

SPELL: 1. behaviour 